\title{
CALIBRATING AND EVALUATING FILTER PAPER METHOD FOR DETERMINING SOIL MOISTURE CHARACTERISTIC CURVE \\ Omran, W.M. ${ }^{*}$ and B.M. El-Garhy* \\ * Soil science Dept. Fac. of Agric. Minofiya University. \\ ** Civil Engineering Dept. Fac. of Eng. Minofiya University.
}

\begin{abstract}
Three laboratory experiments were conducted to calibrate and evaluate filter paper method for the purpose of soil moisture characteristic curve determination. The objective of this study is developing calibration curve of the filter paper under completely controlled isothermal condition to be used in determining soil moisture characteristic curve.

First experiment was carried out to find out the suitable equilibration time between the filter paper and osmotic suction using $\mathrm{NaCl}$ salt solutions under isothermal conditions.

Second and third experiments were carried out to show the relationships between suction and moisture content of both filter papers and soil samples, respectively.

The obtained results showed that 5 days was enough time to reach equilibrium. Also, both filter paper calibration curve and soil moisture characteristic curve were developed.

The research recommended using filter paper method in determining soil moisture characteristic curve because it is simple, cheap, reliable, and cover a wide range of water potential comparing with other available methods. The research also lead us to further required studies to validate the method at extremely wet and extremely dry soils and also using a comparison with different methods to ensure its accuracy and reliability.

Keywords: filter paper method - isothermal vapor equilibrium - soil moisture characteristic curve.
\end{abstract}

\section{INTRODUCTION}

Soil moisture characteristic curve (SMCC) is one of the most important measurements in fields of soil physics and civil engineering as it gives indication about the ability of soil to store water and the availability of such water, soil aeration and soil pore size distribution. There are limitations of using the methods of measuring SMCC regarding its measurement range and cost.

Bulut et al (2001) reported that: the filter paper method (FPM), as a method for measuring soil suction, was evolved in Europe in the 1920s and to USA in 1937 with Gardner (1937). Sibley and Williams 1990 added that the FPM has been in use for many years and owes its attraction to its simplicity. The FPM can usefully cover a wide range of soil water potential (Fawcett and Collis-George, 1967).

The FPM measures soil suction indirectly by simply measuring the moisture content of a filter paper (which have been brought to equilibrium with the soil) and the soil. The suction of the filter paper and hence of the soil, is then obtained from the measured moisture content via calibration curve of the filter paper (Sibley et al., 


\section{El-Sharkawy, Z.A.}

1990). The calibration curve is achieved by measuring the moisture content of filter paper at known values of suction using salt solutions under isothermal conditions.

Bulut et al (2001) stated that: the calibration for the suction wetting curve for filter paper using salt solutions is based upon the thermodynamic relationship between total suction (osmotic suction) and relative humidity resulting from a specific concentration of salt in distilled water. He presented the equations and calculated osmotic suction for specified molalities of different salt solutions. The objective of this study is developing calibration curve of the filter paper under completely controlled isothermal condition to be used in estimating SMCC.

\section{MATERIALS AND METHODS}

Whatman No. 42 filter paper was chosen in this experiment.

Such kind was selected because of its constant properties as explained by Sibley et al. (1990) who conducted an experiment using Whatman No. 42 filter paper from different boxes and did not find significant differences between the papers which give confidence of using it.

Physical and chemical analyses of the experimented soil (taken from Faculty of Agriculture, Minofiya University Experimental Farm) performed according to Black et al. (1965) are presented in Tables 1 and 2.

Table 1: Physical analysis of the experimental soil

\begin{tabular}{|l|l|l|l|l|l|l|}
\hline \multicolumn{2}{|l|}{ Particle size distribution, $\%$} & \multirow{2}{*}{ Texture } & \multicolumn{2}{l|}{ Density $\left(\mathbf{g} / \mathbf{c m}^{3}\right)$} \\
\cline { 1 - 1 } C. sand & F. sand & Silt & Clay & & Real & Bulk \\
\hline 1.98 & 18.81 & 26.38 & 52.83 & Clayey & 2.64 & 1.30 \\
\hline
\end{tabular}

Table 2: Chemical analysis for the experimental soil

\begin{tabular}{|c|c|c|c|c|c|c|c|c|c|c|c|}
\hline \multirow{3}{*}{$\begin{array}{l}\mathrm{CaCO}_{3} \\
(\%)\end{array}$} & \multirow{3}{*}{$\begin{array}{l}\text { Organic } \\
\text { matter } \\
(\%)\end{array}$} & \multirow{3}{*}{$\begin{array}{l}\text { EC } \\
\mathrm{ds} / \mathrm{m}\end{array}$} & \multirow{3}{*}{ pH } & \multicolumn{8}{|c|}{ Soluble ions, meq/100 g soil } \\
\hline & & & & \multicolumn{4}{|c|}{ Cations } & \multicolumn{4}{|c|}{ Anions } \\
\hline & & & & $\mathrm{Ca}^{2+}$ & $\mathbf{M g}^{2+}$ & $\mathrm{Na}^{+}$ & $\mathbf{K}^{+}$ & $\mathrm{CO}_{3}{ }^{2-}$ & $\mathrm{HCO}_{3}^{-}$ & $\mathrm{Cl}^{-}$ & $\mathrm{SO}_{4}^{2-}$ \\
\hline 1.95 & 1.80 & 0.36 & 7.35 & 0.67 & 0.63 & 1.22 & 0.24 & ----- & 0.94 & 1.30 & 0.52 \\
\hline
\end{tabular}

Three laboratory experiments were conducted to find out suitable equilibration time, filter paper calibration curve, and soil moisture characteristic curve (SMCC).

First experiment: Four different equilibration times (i.e. 5, 7, 10, 12 days) were studied to select a suitable equilibration time to be followed in this experiment. 
Salt solutions and filter papers were brought to equilibrium through vapor flow at isothermal conditions based on the following thermodynamic relationship (Bulut et al. 2001):

$$
\psi=v \operatorname{RTm} \varnothing
$$

where: $\psi$ total potential, $v$ number of ions in one molecule of $\mathrm{NaCl}$ (i.e. 2), $\mathrm{R}$ universa gas constant, $T$ absolute temperature, $\mathrm{m}$ molality, and $\varnothing$ osmotic coefficient.

The salt concentrations and their relative potentials were taken from Hamer and Wu (1972).

To ensure isothermal conditions (eliminate temperature fluctuations), the desiccators used in this experiment, were placed in an incubator. This also allows us to choose a specific temperature degree (e.g. $25 \circ \mathrm{C}$ ), in dissimilarity with the previous studies which used water bath or insulated box or room air condition for that purpose.

The incubator, under consideration, has two shelves each one is wide enough for three desiccators. Two filter papers were placed in each desiccator. Each filter paper was supported on a removed bottom plastic cup standing on a mesh grid over a salt solution with a known concentration. So, six desiccators are brought to equilibrium together, which allow measurements of three different solutions with four replicates (i.e. 2 desiccators $\times 2$ papers for each salt solution) at the same time.

Three $\mathrm{NaCl}$ salt solutions of molalities $0.5,1$ and 2 are used to find out required equilibration time.

The wet equilibrated filter papers were weighted very quickly (by two persons as suggested by Bulut et al., 2001) to nearest $0.0001 \mathrm{~g}$. Also the lids of the cans were closed upon removal from the oven and left for 30 seconds to cool before weighing (Al-Khafaf and Hanks, 1972).

Same procedure was followed in the second experiment using $16 \mathrm{NaCl}$ salt solutions, different in their molalities. Osmotic coefficients and osmotic suction (total suction) for the chosen solutions are presented in Table 3.

Table 3: Osmotic coefficients of different molalities of $\mathrm{NaCl}$ salt solutions at $25 \dot{\mathrm{C}}$

\begin{tabular}{|c|c|c|c|c|c|c|c|c|}
\hline $\mathbf{m}, \mathbf{~ m o l} / \mathbf{L}$ & 0.001 & 0.005 & 0.010 & 0.050 & 0.100 & 0.300 & 0.400 & 0.500 \\
\hline$\varnothing$ & 0.998 & 0.984 & 0.968 & 0.944 & 0.933 & 0.921 & 0.920 & 0.921 \\
\hline $\boldsymbol{\Psi}, \mathbf{b a r}$ & 0.05 & 0.24 & 0.48 & 2.3 & 4.6 & 13.7 & 18.2 & 22.8 \\
\hline $\mathbf{m , ~ m o l} / \mathbf{L}$ & 0.800 & 1.000 & 2.000 & 3.000 & 4.000 & 4.500 & 5.000 & 6.000 \\
\hline$\varnothing$ & 0.929 & 0.936 & 0.984 & 1.045 & 1.116 & 1.153 & 1.191 & 1.270 \\
$\boldsymbol{\Psi}, \mathbf{b a r}$ & 37 & 46 & 96 & 155 & 221 & 257 & 295 & 377 \\
\hline
\end{tabular}

Third experiment: A plastic tube, with diameter about $5 \mathrm{~cm}$, was used to prepare soil cores each one being $5 \mathrm{~cm}$ in its height. 14 soil cores and 14 rings with height $2 \mathrm{~mm}$ 


\section{El-Sharkawy, Z.A.}

were prepared and used to perform non-contact technique between the filter paper and soil. Each soil core holds more than $100 \mathrm{gram}$ of undisturbed soil. The soil samples in the cores were brought to saturation at different times and left to dry to allow different soil moisture contents. The soil samples with different unknown moisture content were placed in desiccators. Each one contained two cores. A ring was placed above each soil core and a filter paper was placed above the ring to ensure non-contact. Seven desiccators were used to develop SMCC with four replicates of each point ( 2 papers $\times$ desiccators). The desiccators were placed in the incubator at $10 \circ \mathrm{C}$ (to reduce evaporation) and left for 5 days to reach equilibrium. After that the moisture content of the filter papers and soil samples were determined. More details about methodology could be found in Klute (1986) and Deka et al. (1995), Bulut et al (2001) and McDowell (2004).

\section{RUSULTS AND DISCUSSION}

Unnecessary treatments

The following discussion shows some unnecessary treatments, used to be followed in filter paper experiments. The discussion was done based on the observation and followed technique of this experiment and the revision of the literature of method.

I. Placing a magnetic stirrer bar in each desiccator to allow daily stirring of the salt solutions without opening the desiccators lids (Sibley et al. 1990).

The experiment proved that no need of such treatment because no sedimentation was observed of any salt solution. We used pure salt and redistilled water. Moreover, opening the incubator every day will cause temperature variation and affect the equilibration.

II. Pre-treating the filter papers with fungicides and or bacteria inhibitors as suggested by some authors (Fawcett and Collis-George, 1967 ; McQueen and Miller, 1968 ; Al-Khafaf and Hanks, 1972). However, no fungal degradation or bacteria decomposition was observed on the filter paper during the experiment. Such result was agreed upon with Sibley and Williams (1990) and Smith and Mullins (2001), who found that fungicides are not necessary for 10 and 7 days equilibration time respectively.

III. Removing soil residuals from the filter paper. In this respect, Gardner (1937) suggested a correction procedures for the soil adhering to the filter paper by removing it from the dry paper by fine bush or fingernail and weighting soil dry mass and then water mass could be calculated according to soil water content. Fawcett and Collis-George(1967) reported that: it is possible to use a stake of three papers and use only the central one. However, Smith and Mullins (2001) found this procedures is less accurate because the central paper does not always reach equilibrium. Al-Khafaf and Hanks (1972) studied the three possible ways of contact between the filter paper and the soil sample. He also stated that: filter paper may wet to a different water content if there is significant liquid flow from the soil to the filter paper than if there is only vapor flow. Some other authors (Ridley and Burland, 1993; Sibley et al., 1990; Likos and Lu 2003) reported that the good contact (sandwich the filter paper between two soil cores sealed together) is a measure of soil matric suction and the non-contact (separation the filter paper than soil by a $2 \mathrm{~mm}$ rubber ring) is a measure of total suction of the soil. If we added this to the difficulty of removing the adhering soil particle from the filter paper and our knowledge that the matric suction is consider 
equal to total suction in non-saline soil we have chosen the non-contact technique to follow in this experiment.

The statistical analysis of data obtained of the first experiment did not show significant differences between the water content of the filter papers for the four studied equilibration times. So the lowest one (i.e. 5 days) was chosen.

This result somewhat agree with Deka et al. (1995) who found that at least 6 days are required to reach full equilibrium.

Such relatively short equilibration time may be obtained due to the constant temperature condition which consider the main factor affecting equilibration.

Al-Khafaf and Hanks (1972) and Campbell and Gee (1986) found that absolute temperature did not significantly affect water content of the filter paper in contrast with temperature variations.

Soil water potential (bar) and measured water content of the filter paper are presented in Table 4.

Table 4: Water potential versus filter paper water content

\begin{tabular}{|c|c|c|c|c|c|c|c|c|}
\hline $\boldsymbol{\Psi}$, bar & 0.05 & 0.24 & 0.48 & 2.3 & 4.6 & 13.7 & 18.2 & 22.8 \\
\hline WC, \% & 0.78 & 0.79 & 0.77 & 0.65 & 0.63 & 0.49 & 0.43 & 0.39 \\
\hline $\boldsymbol{\Psi}$, bar & 37 & 46 & 96 & 155 & 221 & 257 & 295 & 377 \\
\hline WC, \% & 0.33 & 0.28 & 0.23 & 0.22 & 0.13 & 0.11 & 0.1 & 0.08 \\
\hline
\end{tabular}

The calibration curve of the filter paper (second experiment), existed in Fig. 1, representing the relationship between the moisture content of the filter paper and water potential of the desiccator atmosphere in $\mathrm{pF}$ scale to obtain linear relations. Based on the obtained curve there is an inflection point (representing air entry point) which could be separated in two regretted lines. 


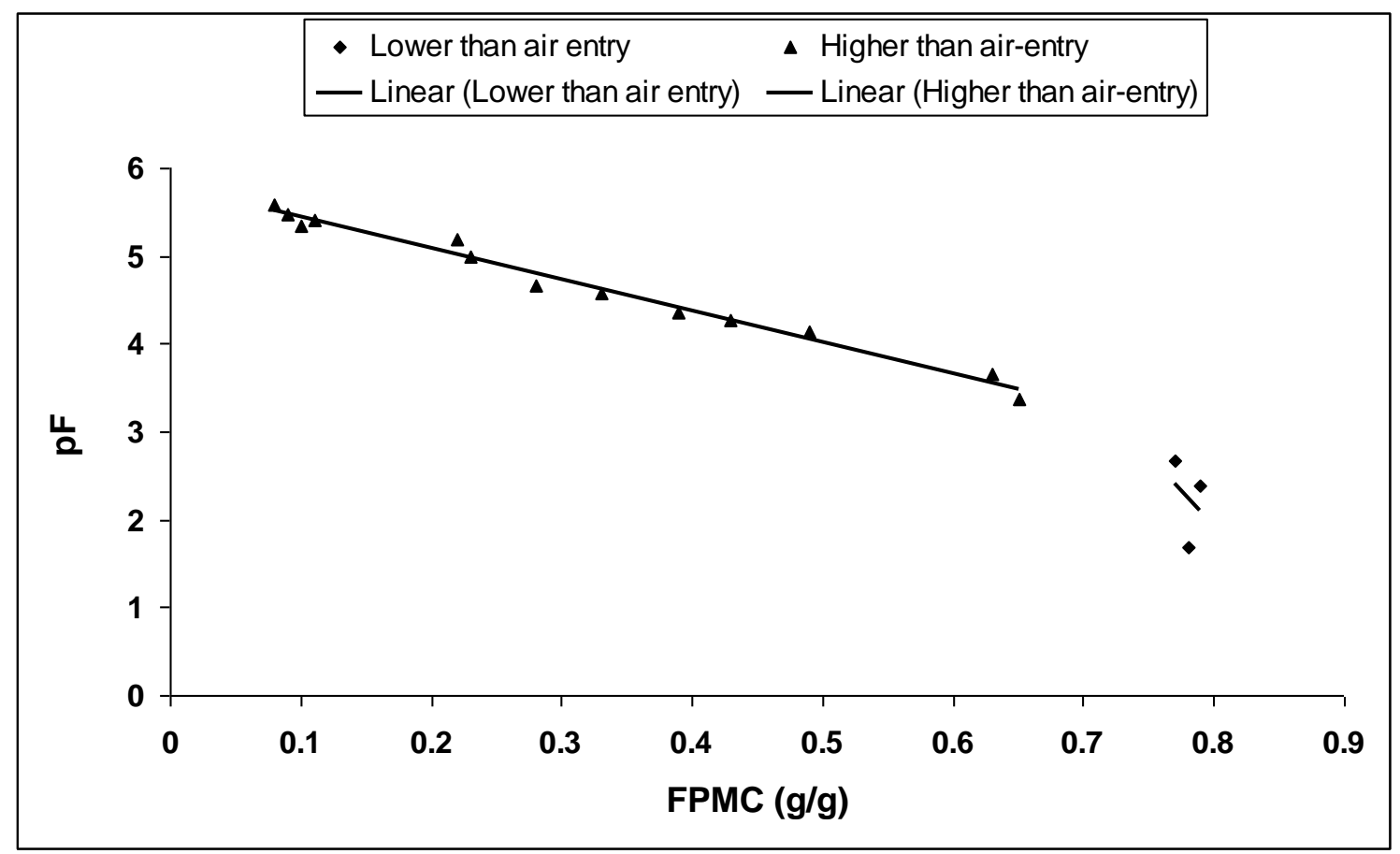

Where: FPMC is moisture content

Fig 1: Filter paper calibration curve

The shape of the obtained curve (fig 1 ) has similar shape to the common SMCC which indicate that the filter paper calibration curve could be used to calculate SMCC. Fig 1 clearly shows the wet end or saturation section, where the suction is lower than its air entry value and FPMC obtained at water potential ranging between $3.4: 5.6$ in $\mathrm{pF}$ scale (suction higher than air entry value).

The first part of the curve (saturation) including the area near field capacity indicate that water content of the filter paper is not very sensitive to water potential changes at the wet end, which agreed upon with some previous studies (Al-Khafaf and Hanks, 1972; Deka et al., 1995; Likos and Lu, 2003). The suggested reason of such result was due to liquid water flow from the soil to filter paper which may tend to absorb more water when it was placed in good contact with the soil (Al-Khafaf and Hanks, 1972). Such explanation does not make sense in our case because non-contact technique was followed. The suggested reason of that is may be due to the considerable differences between the properties of the two porous materials (e.g. soil and filter paper) which may did not ensure constant relationship between water potential and water content of the filter paper through that potential range in contrast with soil. More frequent suction values are required for accurate and reliable results. Actually, the previous result can not ensure that FPM is not valid during that range because the evaluation was done based on three points which are not enough to judge the method performance. So, farther study is recommended to evaluate that range of suction and also the high potential at residual water content and higher more frequently and compare it with soil using isothermal vapor adsorption. Different salts could be used for that purpose. The methodology have been described by Hamer 
and $\mathrm{Wu}, 1972$ and or Schoofield, 1935.

The $\mathrm{pF}$ scale of water potential was chosen to obtain linear relation, with FPMC $(\mathrm{g} / \mathrm{g})$. The obtained equation, representing the calibration curve and its $R^{2}$ are as follows:

$$
\mathrm{pF}=-3.5678 \mathrm{FPMC}+5.797
$$

$R^{2}=0.9833$

Equation 1 relate water suction $(\mathrm{pF})$ to any FPMC during the previously specified range which could be used in predicting SMCC when the MC of the filter paper and soil equilibrated with are determined (third experiment). The high value of $\mathrm{R}^{2}$ gives confidence about the obtained relationship through the specified pF range.

The obtained moisture content values of the filter paper equilibrated with soil were presented in Fig 2.

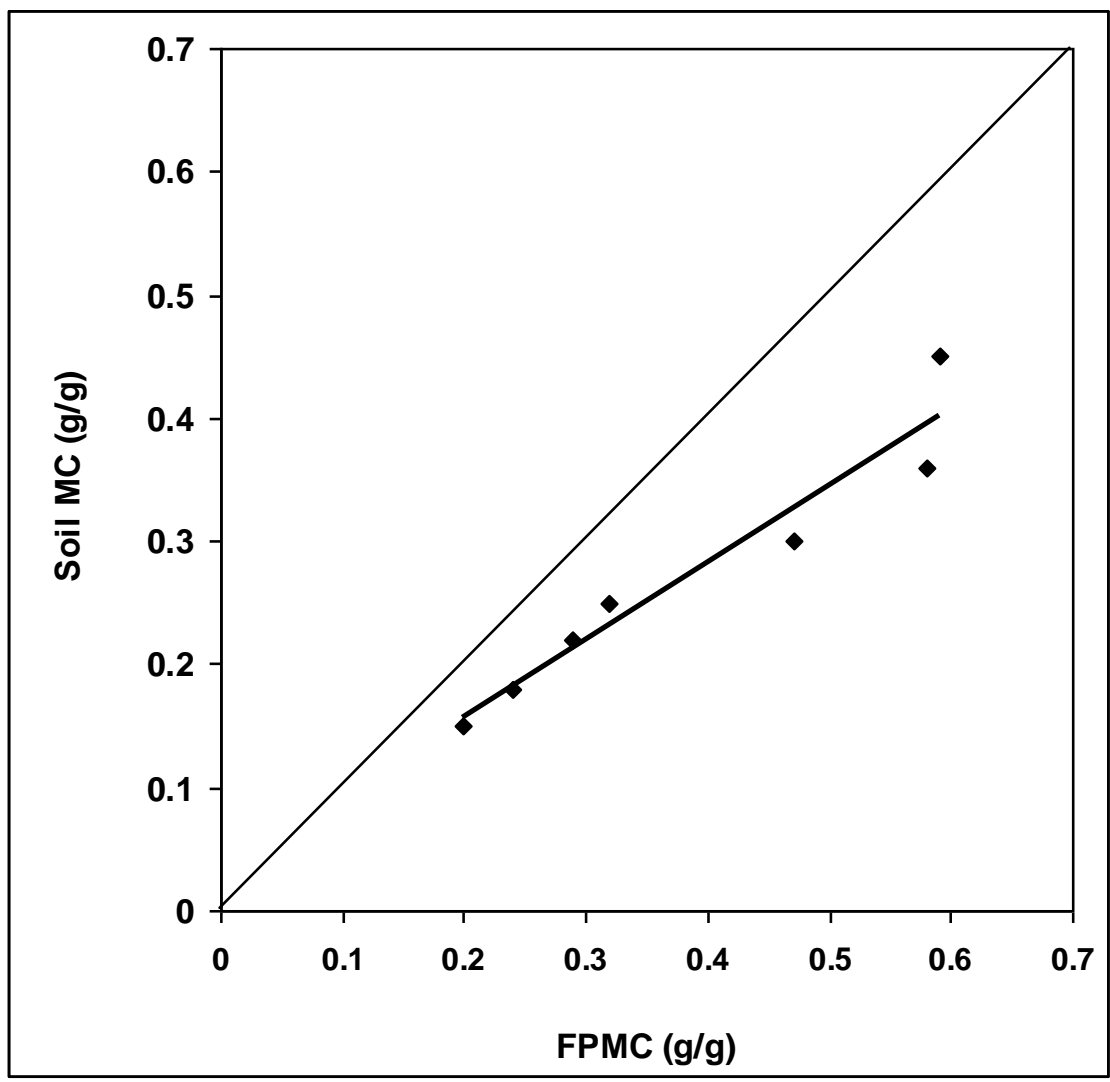

Fig 2:Linear regression of moisture content of filter paper versus soil

Plotting measured moisture contents of the soil versus the filter paper reveal the type and the correlation of the relationship between them. Fig 2 indicate a linear relation with $\mathrm{R}^{2}=0.9297$.

The obtained equation was:

Soil MC $=0.6311 \mathrm{FPMC}+0.0303$ 


\section{EI-Sharkawy, Z.A.}

Equation 2 indicate that soil moisture content is lower than FPMC in the case of noncontact technique.

After determining soil and filter paper moisture contents the water suction values were obtained using filter paper calibration curve as illustrated in equation 1 . The determined SMCC is presented in Fig3.

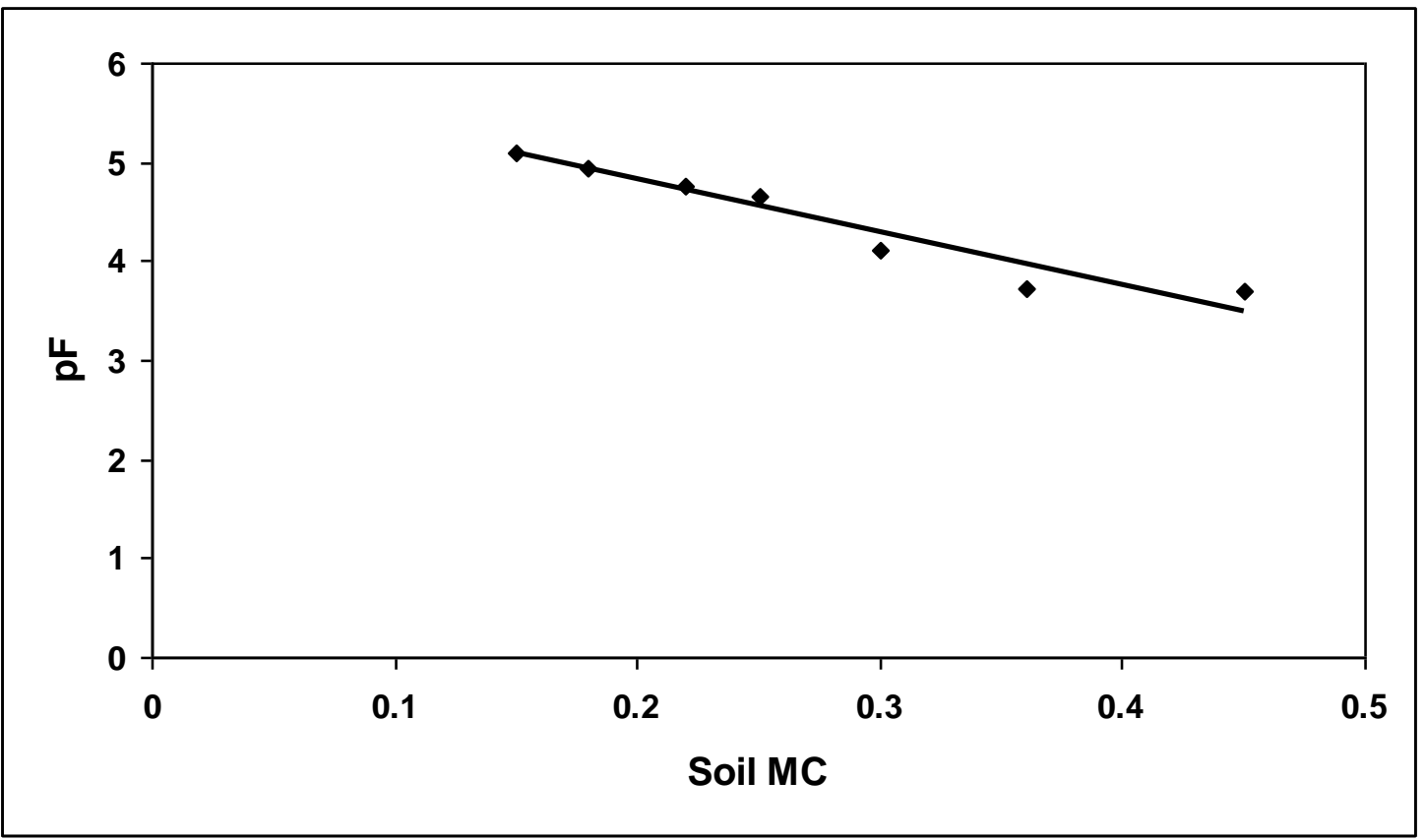

Fig 3:Determined soil moisture characteristic curve using filter paper method

The following equation (equation 3) could be illustrated from fig 3 to describe SMCC.

$$
\mathrm{pF}=-5.3157 \mathrm{FPMC}+5.8807 \quad \text { (3) } \quad \mathrm{R}^{2}=0.9297
$$

The results showed that SMCC could be obtained using filter paper method. The developed curve could be evaluated using different methods in further studies. Strictly speaking, the suction above the filter papers could be established using pressure membrane apparatus and left to equilibrate with the applied suction in isothermal conditions. On the other hand, the osmotic suctions using salt solutions could be used with the soil samples.

\section{CONCLUSION}

Filter paper is simple, easy, cheap and cover a wide range of water suction.

FPM successfully calculate SMCC with a potential range wider than pressure membrane and all available apparatuses used for that purpose. Further studies are required to evaluate more frequently both of extremely high and low potentials. Also studies are required to evaluate SMCC using different procedures and for different clayey soils using the developed filter paper calibration curve to validate and adopt the 
method for Varity of soils.

\section{REFERENCES}

Al-Khafaf and Hanks, 1972: Evaluation of the filter paper method for estimating soil water potential. Soil Sci. 117 (4): 194-199.

Black, G.A., D.D. Evans, J.L. White, L.E. Ensminger, and F.E. Clerk, 1965: Methods of soil analysis. Parts, 1 and 2. Am. Soc. Agron. Madison, USA.

Bulut, R., R. L. Lytton, and W. K. Wray, (2001): Suction Measurements by Filter Paper, Expansive Clay Soils and Vegetative Influence on Shallow Foundations, ASCE Geotechnical Special Publication No. 115 (eds. C. Vipulanandan, M. B. Addison, and M. Hasen), ASCE, Reston, Virginia, pp. 243-261.

Campbell G.S. and G.W. Gee (1986): Water potential. Miscellaneous methods. In Klute, A. (1986): Methods of soil analysis. Part 1, Physical and Mineralogical Methods. 2nd Ed American Soc. Agron. and Soil Sci., Inc. Madison, Wisconsin USA. pp 619-633.

Deka, R.N., M. Wairiu, P.W. Mtakwa, C.E. Mullins, E.M. Veenendaal and J. Townend (1995): Use and accuracy of the filter paper technique for measurement of soil matric potential. Eur. J. Soil Sci. 46: 233-238.

Fawcett R.G. and N. Collis-George 1967: A filter paper method for determining the moisture characteristic curve of soil. Australian J. experimental agriculture and animal husbandry. 7: 162-167.

Gardner, R. (1937): A method of measuring the capillary tension of the soil moisture over a wide moisture range. Soil Sci. 43: 277-283.

Hamer W.J. and Y.C. Wu 1972: Osmotic coefficients and mean activity coefficients of uni-univalent electrolytes in water at $25 \mathrm{C}$. J. Phys. Chem. Ref. Data 1 (4) 1047-1099.

Klute, A. (1986): Methods of soil analysis. Part 1, Physical and Mineralogical Methods. 2nd Ed 2nd Ed American Soc. Agron. and Soil Sci., Inc. Madison, Wisconsin USA. pp 228-230.

Likos, W.J., and N. Lu (2003): Filter Paper Column for Measuring Transient Suction Profiles in Expansive Clay. TRB 2003 Annual Meeting. Sponsoring Committee: A2L06, Engineering Behavior of Unsaturated Soils. Session: Suction Controlled Testing/Unsaturated Soil Engineering Methods. Using Traditional Laboratory Testing Equipmen. Pp 1-22.

McDowell LA (December 2004): An Alternative Medium for the Measurement of Soil Suction by the Filter Paper Method. Master of Science thesis. The University of Tennessee, Knoxville.

McQueen, I.S. and R.F. Miller (1968): Calibration and evaluation of a widerange gravimetric method for measuring soil stress. Soil Sci. 106: 225231.

Ridley, A.M. and J.B. Burland 1993: A new instrument for the measurement of soil moisture suction. Geotechnique 43 No. 2 pp 321-324.

Schofield, R.K. 1935: The pF of the water in soil. Trans. Int. Cong. Soil Sci., 3rd (2) 37-48. 


\section{El-Sharkawy, Z.A.}

Sibley, J.W. and D.J. Williams 1990: A new filter material for measuring soil suction. American Society for testing and materials pp 381-384.

Sibley, J.W., G.K. Smyth and D.J. Williams 1990: Suction-moisture content calibration of filter papers from different boxes. American Society for testing and materials pp 257-262.

Smith, K.A. and C.E. Mullins 2001: Soil and environmental analysis (physical methods). 2nd Ed. Marcel Dekker, Inc. New York USA. Pp 75-77. 


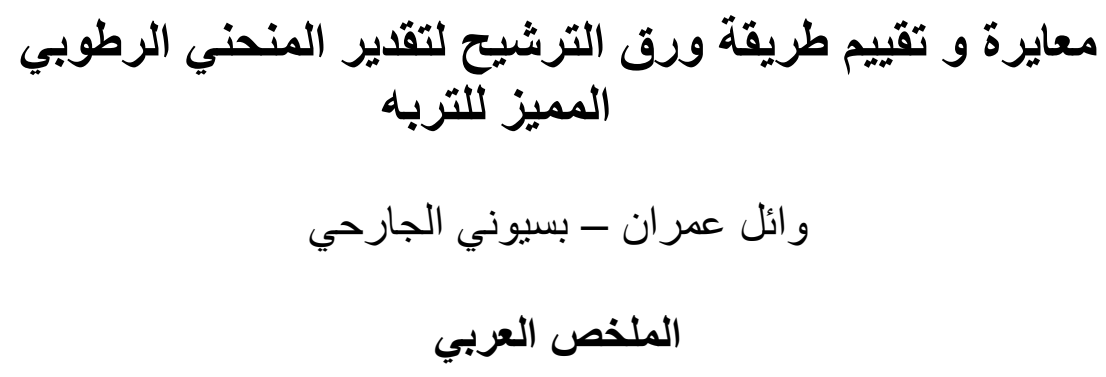

أجريت ثلاث تجارب معملية بغرض معايرة و تقييم طريقة ورق الترشيح و

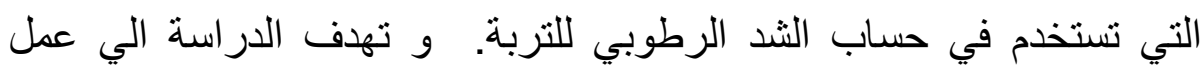

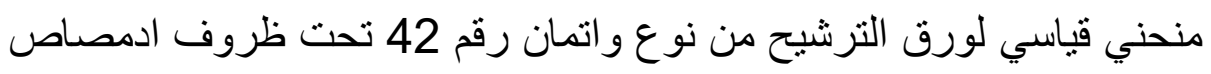
أيزوثرمي مع استخدام هذا المنحني في تقدير المنحني الرطوبي المميز للتربة ونئ.

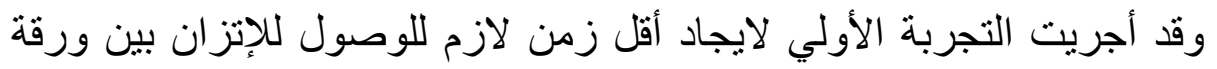

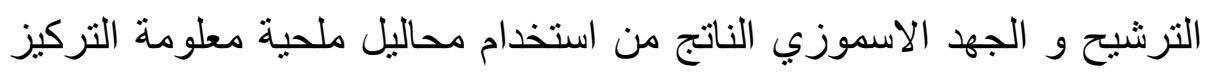

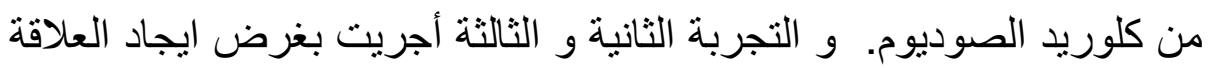
بين الثد الرطوبي و المحتوي الرطوبي لكل من ورق الترشيح و التربة.

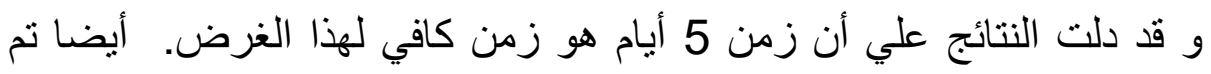

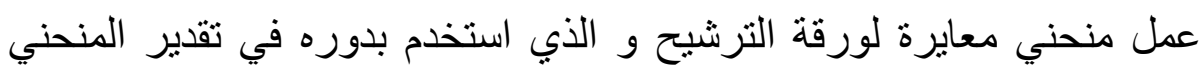

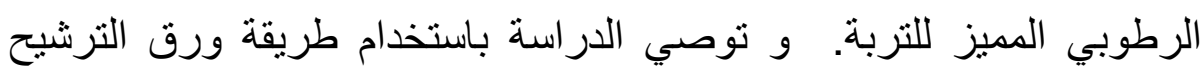

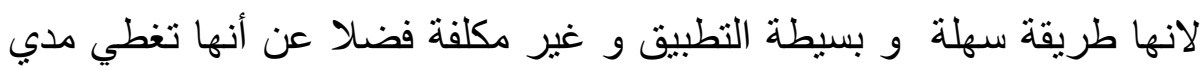

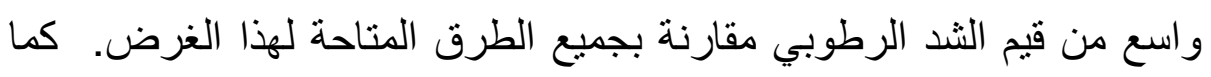

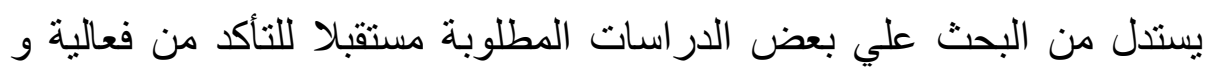

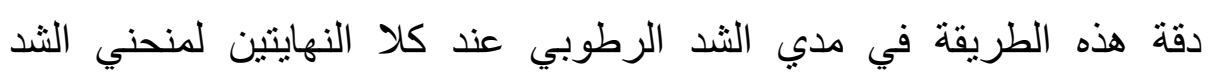
الرطوبي (أقصي ابتلال و أقصي جفاف) ، كما يوصي البحث كذللك بمقارنة

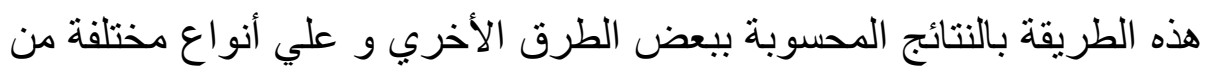


EI-Sharkawy, Z.A.

الأر اضي الطينية.

8028 
J. Agric. Sci. Mansoura Univ., 32 (9): 8017 - 8026, 2007 